\title{
General Practice Registrars' Management of and Specialist Referral Patterns for Atopic Dermatitis
}

\author{
Anneliese Willems ${ }^{1,2}$, Amanda Tapley ${ }^{3,4}$, Alison Fielding ${ }^{3,4}$, Vivian Tng ${ }^{5}$, \\ Elizabeth G. Holliday ${ }^{3}$, Mieke L. van Driel ${ }^{6}$, Jean I. Ball7, Andrew R. Davey, \\ Kristen FitzGerald ${ }^{8,9}$, Neil A. Spike ${ }^{1,2}$, Parker J. Magin ${ }^{3,4}$
}

\begin{abstract}
1 Eastern Victoria GP Training, General Practice Training Organisation, Melbourne, VIC, Australia 2 The University of Melbourne, Department of General Practice, Melbourne, VIC, Australia

3 The University of Newcastle, School of Public Health and Medicine, Callaghan, NSW, Australia

4 GP Synergy, Regional Training Organisation, NSW \& ACT Research and Evaluation Unit, Newcastle, NSW, Australia 5 Department of Dermatology, John Hunter Hospital, Newcastle, NSW, Australia 6 The University of Queensland Faculty of Medicine, Primary Care Clinical Unit, Brisbane, QLD, Australia

7 Hunter Medical Research Institute, Clinical Research Design, IT and Statistical Support Unit (CReDITSS), New Lambton, NSW, Australia 8 University of Tasmania, School of Medicine, Hobart, TAS, Australia

9 General Practice Training Tasmania (GPTT), Regional Training Organisation, Hobart, TAS, Australia
\end{abstract}

Key words: atopic dermatitis, eczema, referral and consultation, general practice, dermatologist

Citation: Willems A, Tapley A, Fielding A, Tng V, Holliday EG. Van Driel ML, Ball JI, Davey AR, FitzGerald K, Spike NA, Magin PJ. General practice registrars' management of and specialist referral patterns for atopic dermatitis. Dermatol Pract Concept. 2021;11(1):e2021118. DOI: https://doi.org/10.5826/dpc.1101a118

Accepted: July 26, 2020; Published: January 29, 2021

Copyright: $\odot 2021$ Willems et al. This is an open-access article distributed under the terms of the Creative Commons Attribution License BY-NC-4.0, which permits unrestricted noncommercial use, distribution, and reproduction in any medium, provided the original author and source are credited.

Funding: The ReCEnT project was funded from 2010 to 2015 by the participating educational organisations: General Practice Training Valley to Coast, the Victorian Metropolitan Alliance, General Practice Training Tasmania, Adelaide to Outback GP Training Program, and Tropical Medical Training, all of which were funded by the Australian Department of Health. From 2016-2019, ReCEnT was funded by an Australian Department of Health commissioned research grant and supported by GP Synergy Regional Training Organisation. GP Synergy is funded by the Australian Department of Health. This project has ethics approval through University of Newcastle's Human Research Ethics Committee: H-2009-0323.

Competing interests: The authors have no conflicts of interest to disclose.

Authorship: All authors have contributed significantly to this publication.

Corresponding author: Parker J. Magin, MBBS, PhD, School of Medicine and Public Health, The University of Newcastle, University Drive, Callaghan, NSW, 2308, Australia. Email: parker.magin@newcastle.edu.au

ABSTRACT Background: Atopic dermatitis (AD) is a common presentation in the general practice (GP) setting. Implementation of appropriate referral pathways is instrumental for best patient care and is an essential skill for Australian GP registrars .

Objectives: We aimed to explore the prevalence and associations of GP registrar referrals to specialists for $\mathrm{AD}$ management.

Methods: A cross-sectional analysis utilizing data from the Registrar Clinical Encounters in Training (ReCEnT) project, an ongoing cohort study that documents in-consultation clinical and educational 
experience of Australian GP registrars. Registrar, patient, and consultation factors associated with referrals for $\mathrm{AD}$ were established using logistic regression.

Results: A total of 2,783 registrars (96\% response rate) provided data from 381,180 consultations from 2010 to 2019 . A total of 3,285 (0.55\%) of 595,412 diagnoses managed were AD, of which 222 $(6.8 \%)$ resulted in referral. Of these referrals, $70 \%$ were to dermatologists, $17 \%$ to allergists/immunologists, and $10 \%$ to pediatricians. Associations of referral included registrar female gender, patient age, longer consultation duration; an established (rather than new) AD diagnosis; supervisor advice being sought; and learning goals being generated.

Conclusions: Both registrar and patient factors influence $\mathrm{AD}$ referral patterns. Registrars referred established rather than newly diagnosed AD, suggesting a level of comfort in initial management. Referral was associated with longer consultations, seeking supervisor advice, and generation of learning goals-suggesting these are more complex presentations and, possibly, registrar learning opportunities. A significant proportion of referrals were to non-dermatologist specialists. The implication of this for optimal patient care is a subject for further study.

\section{Introduction}

Atopic dermatitis (AD) is associated with psychological, social, and quality-of-life effects in patients and their families [1,2]. AD has a 12 -month prevalence of $16 \%-17 \%$ in childhood and is characterized by chronic inflammation and pruritus [3]. While AD is predominantly a childhood illness [4], an estimated $50 \%$ of those affected by AD in their early years go on to have symptoms into their teenage years and adulthood [5].

Given its prevalence, $\mathrm{AD}$ represents a common presentation in the primary care setting. The majority of $\mathrm{AD}$ is mild and may be managed in primary care, rather than in specialty practice [6]. Skin presentations represent $11 \%$ of all problems encountered by GP registrars. Of these, $12 \%$ are “dermatitis," including $\mathrm{AD}[7]$.

$\mathrm{AD}$ is generally a straightforward clinical diagnosis [8,9], and the treating clinician must first exclude other conditions [6]. Patient education underpins treatment and all cases should be treated with emollients [8]. Topical corticosteroids and, when appropriate, antimicrobial and antiseptic measures, comprise the next level of therapy [8]. This management can be appropriately delivered in primary care. In moderate-severe disease, referral may be necessary for access to additional therapies such as narrowband UVB phototherapy or oral immunosuppressive therapies [10]. Additionally, a specialist's opinion may occasionally be needed for clarification of diagnosis or for exploration of exacerbating factors, such as allergy [6].

With a breadth of management options available according to severity of $\mathrm{AD}$ disease, it is important for clinicians to have confidence in diagnosis and early stages of management [9]. Similarly, clinicians should be competent in recognizing disease severity and have a good understanding of the indications for referral [6]. This may be problematic in primary care. Some studies have suggested that GPs may lack confidence in diagnosis $[11,12]$ and management of skin disease $[11,13,14]$. GPs and vocational trainees in specialist general practice (GP registrars) have limited formal training in managing skin disease $[7,13,15]$. There is relatively little teaching of dermatology during medical school $[16,17]$. Dermatology placements are infrequent in junior doctor rotations and, as such, the bulk of dermatology learning takes place in-practice during postgraduate terms [16]. Consequently, skin disease remains a learning-need for GP registrars, and GP registrars find skin consultations problematic compared to non-skin consultations [7].

There is also a lack of evidence regarding appropriate circumstances for a GP referral of skin diseases [18,19]. Given the historical challenges of GP registrar management of skin disease, the frequency of AD in Australia, and the challenges in providing appropriate referrals, we sought to address an evidence gap. In this study we sought to explore the nature, frequency, and associations of GP registrar specialist referrals for $\mathrm{AD}$.

\section{Materials and Methods}

We performed a cross-sectional analysis of data within the Registrar Clinical Encounters in Training (ReCEnT) project. ReCEnT documents the in-consultation educational and clinical experiences of GP registrars.

\section{GP Vocational Training}

GP training in Australia operates under an apprenticeship-like model wherein registrars are supervised by senior accredited GPs within an accredited practice environment. Training 
entails at least 3 6-month, full-time-equivalent, community -based general practice terms.

\section{ReCEnT}

Registrars complete 3 cycles of ReCEnT data collection during training, once each term. Details of 60 consecutive consultations are collected on paper-based Case Report Forms. From these consultations, problems managed and referrals made are coded according to the International Classification of Primary Care (second edition) classification system (ICPC-2 Plus) [20]. Registrar and practice variables are also collected every 6 months. ReCEnT was conducted in up to 5 Regional Training Providers (RTP), across 5 states, during 2010-2015, and in 3 Regional Training Organisations (RTO), across 3 states and 1 territory, from 2016, following a major restructuring of Australian GP vocational training.

\section{This Study}

Data from 2010-2019 is included in the current study. For this study, our analyses were confined to consultations coded as "dermatitis, atopic," "eczema," and "eczema, infantile." See Supplementary Table 1 for a complete list of inclusion and exclusion ICPC-2 Plus codes.

\section{Outcome Factor}

The outcome was "specialist referral made."

\section{Independent Variables}

Independent variables included in these models included registrar, practice, patient, consultation and educational factors. Patient factors were: patient age group, patient gender, Aboriginal or Torres Strait Islander status, and non-English speaking background status. Registrar factors were: registrar age and gender, full-time or part-time employment status, the term of GP training, whether the registrars had worked at their current practice previously, and whether they had qualified as a doctor in Australia. Practice factors were: the size of the practice, whether the practice was fully bulk-billing (that is, no fee charged to the patient), the rurality of the practice, the RTP or RTO the registrar was enrolled with (hereafter "region"), and the socio-economic index for areas,-index of

Table 1. Demographics of Participating GP Registrars and Their Practices

\begin{tabular}{|c|c|c|}
\hline \multicolumn{2}{|c|}{ Registrar Variables $(n=2783)$} & n (\%) \\
\hline \multirow[t]{2}{*}{ Registrar gender } & Male & 1,055 (37.9) \\
\hline & Female & $1,728(62.1)$ \\
\hline \multirow[t]{2}{*}{ Qualified as doctor in Australia } & Yes & $547(19.8)$ \\
\hline & No & $2,223(80.3)$ \\
\hline \multirow[t]{2}{*}{ Pathway registrar enrolled in } & General & $1,930(70.0)$ \\
\hline & Rural & $826(30.0)$ \\
\hline \multicolumn{3}{|c|}{ Registrar Round/Practice Variables $(\mathrm{n}=6414)$} \\
\hline Registrar age (years) & Mean \pm SD & $32.6(6.3)$ \\
\hline \multirow[t]{2}{*}{ Registrar works Full-time or Part-time } & Full-time & $4,770(77.1)$ \\
\hline & Part-time & $1,420(22.9)$ \\
\hline \multirow[t]{3}{*}{ Registrar training term } & Term 1 & $2,640(41.2)$ \\
\hline & Term 2 & $2,091(32.6)$ \\
\hline & Term 3 & $1,683(26.2)$ \\
\hline \multirow[t]{3}{*}{ Practice rurality } & Major city & $3,983(62.7)$ \\
\hline & Inner regional & $1,633(25.7)$ \\
\hline & Outer regional remote & $732(11.5)$ \\
\hline Practice SEIFA-IRSD & Mean \pm SD & $5.5(2.8)$ \\
\hline \multirow[t]{2}{*}{ Practice routinely bulk bills } & Yes & $1,784(28.1)$ \\
\hline & No & $4,566(71.9)$ \\
\hline \multirow[t]{2}{*}{ Registrar worked at practice previously } & Yes & $1,343(21.2)$ \\
\hline & No & $4,988(78.8)$ \\
\hline \multirow[t]{2}{*}{ Practice size } & Small (1-5 GPs) & $2,371(38.4)$ \\
\hline & Large (6-10+ GPs) & $3,811(61.6)$ \\
\hline
\end{tabular}

GP = general practice; SD = standard deviation; SEIFA-IRSD = socio-economic index for area - index of relative socioeconomic disadvantage. 
relative socioeconomic disadvantage (SEIFA-IRSD) in which the practice was located. Consultation factors were: the duration of consultation, number of problems managed within the consultation, whether AD was a new problem, whether the registrar sought assistance for diagnosis or management of the problems managed, whether pathology was ordered, whether follow-up was ordered, whether learning goals were generated, and which medications, if any, were prescribed.

\section{Statistical Analyses}

Statistical analysis was at the level of problem/diagnosis. The proportion of problems/diagnoses that were atopic dermatitis and, of those, the proportion that were referred were calculated with $95 \%$ confidence intervals (CI) and were adjusted for repeated measures within registrars.

Descriptive statistics included frequencies for categorical variables and mean with standard deviation for continuous variables. The frequencies of categorical variables were compared between outcome categories using chi-square tests for all variables, except when Fisher's exact test was used (due to an expected count less than 5 in $25 \%$ or more cells). For continuous variables, means were compared using a t test.

Logistic regression has been used within the generalized estimating equations (GEE) framework to account for repeated measures within registrars. An exchangeable working correlation structure was assumed. Univariate analyses were conducted on each covariate with the outcome. Covariates with a univariate $P$ value $<0.20$ were considered for inclusion in the multiple regression model.

Once the model with all significant covariates was fitted, model reduction was assessed. Covariates that were no longer significant $($ at $\mathrm{P}<0.2)$ in the multivariable model were tested for removal from the model. If the covariate's removal did not substantively change the resulting model, the covariate was removed from the final model. A substantive change to the model was defined as any covariate in the model having a change in the effect size (odds ratio) of greater than $10 \%$.

Diagnostic tests were conducted to assess goodness of fit, using the Hosmer-Lemeshow test for logistic models. Predictors were considered statistically significant if the $\mathrm{P}$ value was $<0.05$.

Statistical analyses used STATA 14.1 (StataCorp, College Station, TX, USA) and SAS V9.4 (SAS Institute Inc., Cary, NC, USA).

This project has ethics approval through an appropriate Human Research Ethics Committee.

\section{Results}

In total, 2,783 registrars (96.1\% response rate) provided data from 381,180 consultations from 2010-2019, including 595,412 problems managed. Table 1 shows the demographics of participating registrars.
Table 2. Referrals for Atopic Dermatitis $(\mathrm{n}=222)$

\begin{tabular}{|l|c|c|}
\hline \multicolumn{1}{|c|}{ Specialist } & Frequency & Percentage \\
\hline Dermatologist referral & 153 & 70 \\
\hline $\begin{array}{l}\text { Allergist/immunologist } \\
\text { referral }\end{array}$ & 38 & 17 \\
\hline Pediatrician referral & 21 & 9.6 \\
\hline Referral to clinic/center & 4 & 3.2 \\
\hline Other & 3 & 1.4 \\
\hline Total & $\mathbf{2 1 9}$ & 100 \\
\hline
\end{tabular}

Note: Three referrals were excluded, as they did not specify the referral type and hence have been removed from analysis.

Of all problems, 3,285 (0.55\% [95\% CI: 0.53, 0.57]) were AD. Of all AD problems, 222 (6.8\% [95\% CI: 6.0, 7.7]) were referred. Of these referrals, $70 \%$ were to dermatologists (Table 2 ), $17 \%$ to allergists/immunologists, $10 \%$ to pediatricians, and $3 \%$ to a clinic without specifying the specialist.

The characteristics associated with specialist referral are presented in Table 3. As well as the associations with referral, overall findings of note are that for $9.7 \%$ of $\mathrm{AD}$ problems, supervisor advice or assistance was sought and for $18 \%$ of AD problems learning goals were generated.

The results of univariate and multivariable logistic regression are presented in Table 4.

Statistically significant multivariable associations of an $\mathrm{AD}$ problem being referred to a specialist included registrar female gender (OR 1.49 [95\% CI: 1.05, 2.12]) and being Australian-trained (OR 2.02 [1.18, 3.48]); patient age (patients aged $0-1$ year less likely to be referred [OR 0.58 [0.34, 0.98] compared to patients aged 2-12 years); AD being an existing problem (OR 0.28 [0.18, 0.43] for a new problem); pathology being ordered (OR 2.48 [1.08, 5.69]); and learning goals being generated (OR 2.57 [1.69 3.90]).

Also significant in multivariable analyses, less non-AD problems, on average, were addressed in consultations resulting in referral (OR 0.57 [95\% CI: 0.43, 0.75]), and these consultations were longer (OR 1.05 [95\% CI: 1.02, 1.07] for each additional minute of consultation duration). In univariate analysis (Table 3), referral was associated with an estimated average increase of 3 minutes in AD consultation duration.

In $\mathrm{AD}$ consultations resulting in referral, supervisors were more likely to provide the registrar with advice or assistance ( $20 \%$ versus $9 \%$ ), which was significant on multivariable analysis (OR 1.73 [95\% CI: 1.06, 1.83]).

\section{Discussion}

The associations of GP and GP registrar referrals for AD have not been well investigated. To our knowledge this is the first analysis exploring Australian GP registrars' (or GP trainees in other countries) referrals for AD. This study 
Table 3. Characteristics by Referral Status in Atopic Dermatitis Consultations ( $\mathrm{n}=381,180$ )

\begin{tabular}{|c|c|c|c|c|c|}
\hline & & & Referr & for Atopic De & itis \\
\hline Factor Group & Variable & Class & No & Yes & P value \\
\hline Patient factors & Patient age group & $0-1$ years & $655(22 \%)$ & $32(15 \%)$ & 0.12 \\
\hline & & $2-12$ years & $834(28 \%)$ & $67(31 \%)$ & \\
\hline & & $13-24$ years & $542(18 \%)$ & $49(23 \%)$ & \\
\hline & & $25-44$ years & $541(18 \%)$ & $38(18 \%)$ & \\
\hline & & $45+$ years & $441(15 \%)$ & $30(14 \%)$ & \\
\hline & Patient gender & Male & $1,318(44 \%)$ & $93(43 \%)$ & 0.89 \\
\hline & & Female & $1,677(56 \%)$ & $121(57 \%)$ & \\
\hline & NESB & No & $2,589(90 \%)$ & $187(88 \%)$ & 0.40 \\
\hline & & Yes & $290(10 \%)$ & $25(12 \%)$ & \\
\hline & Patient/practice status & Existing patient & $1,009(34 \%)$ & $88(40 \%)$ & 0.12 \\
\hline & & New to registrar & $1,722(57 \%)$ & $111(51 \%)$ & \\
\hline & & New to practice & $272(9 \%)$ & $20(9 \%)$ & \\
\hline & $\begin{array}{l}\text { Aboriginal or Torres Strait } \\
\text { Islander }\end{array}$ & No & $2,826(99 \%)$ & $210(99.5 \%)$ & 0.52 \\
\hline & & Yes & $38(1 \%)$ & $1(0.5 \%)$ & \\
\hline Registrar factors & Registrar gender & Male & $1,131(37 \%)$ & $69(31 \%)$ & 0.078 \\
\hline & & Female & $1,932(63 \%)$ & $153(69 \%)$ & \\
\hline & $\begin{array}{l}\text { Registrar full-time or } \\
\text { part-time }\end{array}$ & Part-time & $733(25 \%)$ & $57(27 \%)$ & 0.48 \\
\hline & & Full-time & $2,249(75 \%)$ & $156(73 \%)$ & \\
\hline & Term & Term 1 & $1,194(39 \%)$ & $94(42 \%)$ & 0.39 \\
\hline & & Term 2 & $1,122(37 \%)$ & $71(32 \%)$ & \\
\hline & & Term 3 & $747(24 \%)$ & $57(26 \%)$ & \\
\hline & $\begin{array}{l}\text { Worked at practice } \\
\text { previously }\end{array}$ & No & $2,383(79 \%)$ & $180(82 \%)$ & 0.33 \\
\hline & & Yes & $631(21 \%)$ & $40(18 \%)$ & \\
\hline & $\begin{array}{l}\text { Qualified as doctor in } \\
\text { Australia }\end{array}$ & No & $503(16 \%)$ & $29(13 \%)$ & 0.18 \\
\hline & & Yes & $2,547(84 \%)$ & $192(87 \%)$ & \\
\hline & Registrar age & Mean (SD) & $32(6)$ & $32(6)$ & 0.74 \\
\hline Practice factors & Practice size & Small & $1,069(36 \%)$ & $76(36 \%)$ & 0.90 \\
\hline & & Large & $1,906(64 \%)$ & $138(64 \%)$ & \\
\hline & Practice routinely bulk bills & No & $2,132(71 \%)$ & $151(69 \%)$ & 0.49 \\
\hline & & Yes & $879(29 \%)$ & $69(31 \%)$ & \\
\hline & Rurality & Major city & $2,075(69 \%)$ & $164(76 \%)$ & 0.090 \\
\hline & & Inner regional & $685(23 \%)$ & $41(19 \%)$ & \\
\hline & & $\begin{array}{l}\text { Outer regional } \\
\text { remote }\end{array}$ & $262(9 \%)$ & $12(6 \%)$ & \\
\hline & Region & Region 1 & $518(17 \%)$ & $28(13 \%)$ & 0.37 \\
\hline & & Region 2 & $139(5 \%)$ & $14(6 \%)$ & \\
\hline & & Region 3 & $374(12 \%)$ & $22(10 \%)$ & \\
\hline & & Region 4 & $1,300(42 \%)$ & $97(44 \%)$ & \\
\hline & & Region 5 & $28(0.9 \%)$ & $3(1 \%)$ & \\
\hline & & Region 6 & $506(17 \%)$ & $44(20 \%)$ & \\
\hline & & Region 7 & $198(6 \%)$ & $14(6 \%)$ & \\
\hline & SEIFA-IRSD & Mean (SD) & $6(3)$ & $6(3)$ & 0.098 \\
\hline
\end{tabular}

(Table 3 continues) 
Table 3. Characteristics by Referral Status in Atopic Dermatitis Consultations ( $\mathrm{n}=\mathbf{3 8 1 , 1 8 0}$ ) (continued)

\begin{tabular}{|c|c|c|c|c|c|}
\hline \multirow[b]{2}{*}{ Factor Group } & \multirow[b]{2}{*}{ Variable } & \multirow[b]{2}{*}{ Class } & \multicolumn{3}{|c|}{ Referral for Atopic Dermatitis } \\
\hline & & & No & Yes & P value \\
\hline \multirow{13}{*}{$\begin{array}{l}\text { Consultation } \\
\text { factors }\end{array}$} & New problem seen & No & $1,791(65 \%)$ & $166(85 \%)$ & $<0.001$ \\
\hline & & Yes & $959(35 \%)$ & $30(15 \%)$ & \\
\hline & Sought help any source & None & $2,367(77 \%)$ & $138(62 \%)$ & $<0.001$ \\
\hline & & Supervisor & $274(9 \%)$ & $45(20 \%)$ & \\
\hline & & Other sources & $422(14 \%)$ & $39(18 \%)$ & \\
\hline & Pathology ordered & No & $3,004(98 \%)$ & $211(95 \%)$ & 0.004 \\
\hline & & Yes & $59(2 \%)$ & $11(5 \%)$ & \\
\hline & Follow-up ordered & No & $1,963(64 \%)$ & $131(59 \%)$ & 0.13 \\
\hline & & Yes & $1,100(36 \%)$ & $91(41 \%)$ & \\
\hline & Learning goals generated & No & $2,339(82 \%)$ & $128(61 \%)$ & $<0.001$ \\
\hline & & Yes & $523(18 \%)$ & $81(39 \%)$ & \\
\hline & Consultation duration & Mean $(\mathrm{SD})$ & $17(8)$ & $20(9)$ & $<0.001$ \\
\hline & Number of problems & Mean $(\mathrm{SD})$ & $2(1)$ & $2(1)$ & $<0.001$ \\
\hline
\end{tabular}

NESB = Non-English speaking background; SEIFA-IRSD = socio-economic index for areas - index of relative socioeconomic disadvantage; $\mathrm{SD}=$ standard deviation.

Table 4. Characteristics Associated With a Referral Being Made for Atopic Dermatitis

\begin{tabular}{|c|c|c|c|c|c|c|}
\hline \multirow[b]{2}{*}{ Factor Group } & \multirow[b]{2}{*}{ Variable } & \multirow[b]{2}{*}{ Class } & \multicolumn{2}{|c|}{ Univariate } & \multicolumn{2}{|c|}{ Adjusted } \\
\hline & & & OR $[95 \% \mathrm{Cl}]$ & P value & OR $[95 \% \mathrm{Cl}]$ & \\
\hline \multirow[t]{4}{*}{ Patient factors } & \multirow{4}{*}{$\begin{array}{l}\text { Patient age group } \\
\text { Comparator 2-12 } \\
\text { years }\end{array}$} & $0-1$ years & $0.61(0.39,0.95)$ & 0.027 & $0.58(0.34,0.98)$ & 0.0417 \\
\hline & & 13-24 years & $1.13(0.76,1.67)$ & 0.55 & $1.02(0.63,1.63)$ & 0.9444 \\
\hline & & $25-44$ years & $0.87(0.58,1.32)$ & 0.52 & $0.91(0.55,1.50)$ & 0.6988 \\
\hline & & $45+$ years & $0.85(0.54,1.32)$ & 0.47 & $1.23(0.73,2.05)$ & 0.4358 \\
\hline \multirow[t]{2}{*}{ Registrar factors } & Registrar gender & Female & $1.30(0.97,1.74)$ & 0.078 & $1.49(1.05,2.12)$ & 0.0269 \\
\hline & $\begin{array}{l}\text { Qualified as doctor } \\
\text { in Australia }\end{array}$ & Yes & $1.31(0.88,1.93)$ & 0.18 & $2.02(1.18,3.48)$ & 0.0110 \\
\hline Practice factors & SEIFA-IRSD & & $1.04(0.99,1.10)$ & 0.098 & $1.03(0.98,1.10)$ & 0.2550 \\
\hline \multirow{8}{*}{$\begin{array}{l}\text { Consultation } \\
\text { factors }\end{array}$} & New problem seen & Yes & $0.34(0.23,0.50)$ & $<.001$ & $0.28(0.18,0.43)$ & $<.001$ \\
\hline & $\begin{array}{l}\text { Sought help any } \\
\text { source }\end{array}$ & Other sources & $1.57(1.09,2.27)$ & 0.016 & $1.19(0.73,1.97)$ & 0.48 \\
\hline & Comparator: None & Supervisor & $2.82(1.97,4.03)$ & $<.001$ & $1.73(1.06,2.83)$ & 0.030 \\
\hline & Pathology ordered & Yes & $2.65(1.36,5.17)$ & 0.004 & $2.48(1.08,5.69)$ & 0.031 \\
\hline & Follow-up ordered & Yes & $1.24(0.94,1.64)$ & 0.13 & $0.75(0.52,1.09)$ & 0.13 \\
\hline & $\begin{array}{l}\text { Learning goals } \\
\text { generated }\end{array}$ & Yes & $2.83(2.10,3.82)$ & $<.001$ & $2.57(1.69,3.90)$ & $<.001$ \\
\hline & $\begin{array}{l}\text { Consultation } \\
\text { duration }\end{array}$ & & $1.03(1.02,1.05)$ & $<.001$ & $1.05(1.02,1.07)$ & $<.001$ \\
\hline & Number of problems & & $0.69(0.58,0.83)$ & $<.001$ & $0.57(0.43,0.75)$ & $<.001$ \\
\hline
\end{tabular}

SEIFA-IRSD = socio-economic index for areas - index of relative socioeconomic disadvantage 


\section{Supplementary Table 1.}

\begin{tabular}{|l|l|} 
Included Diagnostic Codes & \multicolumn{1}{|c|}{$\begin{array}{c}\text { Excluded Diagnostic } \\
\text { Codes }\end{array}$} \\
\hline $\begin{array}{l}\text { Dermatitis, atopic } \\
\text { Eczema }\end{array}$ & $\begin{array}{l}\text { Rash; atopic } \\
\text { Eczema, infantile }\end{array}$ \\
& $\begin{array}{l}\text { Dermatitis; flexural } \\
\text { Dermatitis; allergic } \\
\text { Dermatitis }\end{array}$ \\
\hline
\end{tabular}

provides several significant findings pertaining to registrar engagement and confidence with $\mathrm{AD}$, frequency of referral, and specialist choice.

\section{Summary of Main Findings}

Registrars referred $6.8 \%$ of AD cases. The dermatologist was the preferred specialist to manage $\mathrm{AD}$, with $70 \%$ of cases referred to this specialty, but a relatively high percentage of cases $(17 \%)$ were referred to allergists/immunologists.

Prominent associations of referrals included longer consultations, a preexisting AD diagnosis, and consultations in which fewer issues were managed. There was increased supervisor involvement for consultations in which AD was referred and considerably increased learning-goal generation for these consultations.

\section{Interpretation of Findings and Comparison With Previous Literature}

The context for our finding of referral of $6.8 \%$ of AD problems is that GPs have previously been shown to refer $10.3 \%$ of all problems managed [21]. In an earlier analysis of this Australian registrar population, we found a referral rate for skin problems of $8.0 \%$. This earlier analysis also found that registrars were $38 \%$ (odds ratio [OR] 0.62) less likely to refer skin problems compared with non-skin problems.

Our results, though, suggest AD remains a significant learning-need for GP registrars. Compared to all problems seen (in previous analyses from ReCEnT), when presented with a diagnosis of $\mathrm{AD}$, a GP registrar is more likely to seek supervisor advice or assistance $(9.7 \%$ compared to $6.9 \%$ for all problems [22]), and generate learning-goals (18.4\% compared to $16.6 \%$ for all problems [23]). This is consistent with previous evidence that diagnosing skin diseases (including $\mathrm{AD}$ ) is an area that receives less attention throughout undergraduate, postgraduate, and specialist training for GP trainees $[7,16,17,24]$. Qualified GPs are also reported to have some difficulty with AD management [13].

The relative frequency of referrals of an existing rather than a new AD problem/diagnosis suggests that, while registrars may need considerable training to manage $\mathrm{AD}$, they may nevertheless be comfortable with $\mathrm{AD}$ diagnosis and initial management. Despite presenting some challenges for the early-career $\mathrm{GP}, \mathrm{AD}$ is most often a straightforward diagnosis, is mostly of mild or moderate severity, and can be managed appropriately by the GP using first-line modalities. It is then likely that the advice and assistance of their supervisor may support registrars' management of AD in the context of them having considerable learning-needs in the area.

It was also apparent that referral for AD may be associated with a more complex or problematic $\mathrm{AD}$ presentation: longer consultation duration, greater learning-goal generation, more supervisor assistance sought, more pathology ordered, and fewer non-AD problems addressed in the index consultation.

Another notable finding of this study was that while the dermatologist is the specialist of choice for $\mathrm{AD}$, a relatively large proportion of patients are referred to allergists/immunologists. The roles of each of these specialists as a part of the multidisciplinary team have previously been recognized in the care of moderate-severe AD [25]. Significantly, the choice of specialist has been shown to influence management practices [26, 27]. Allergists and dermatologists diverge in their recommendations for systemic treatments, adjunctive therapies, and preventative measures [25]. Given the natural emphasis of their training, allergists/immunologists are more likely to focus on preventative strategies and potential allergic triggers [27].

Our results suggest registrars are quite frequently prioritizing allergy pathways in AD management. The $17 \%$ referred to allergists/immunologists may reflect the rise in primary care recognition of the association of eczema with food allergy. A review of studies by Werfel et al. in 2007 found a prevalence of food allergy in 33\%-63\% of cases [28]. The exact relationship between food allergy and AD remains controversial. Food allergy as an aggravating factor of AD in infants and young children is well accepted [29], but there is a lack of consensus regarding food allergy as an exacerbating factor versus a cause $[25,30]$.

It has previously been suggested that primary care providers overemphasize the role of food allergy in AD [30]. Our results also suggest a registrar emphasis on a possible allergic component to $\mathrm{AD}$. Overemphasis on allergies versus the overarching etiology of AD can lead to miscommunication, which results in a parent erroneously believing that a food allergy is causing their child's AD [30]. This can then lead to restrictive diets, risking possible nutritional deficiencies, and diversion from the basics of optimizing AD management such as education, skin care, and optimal use of topical corticosteroids [30].

Referral rates for AD in this study are reflective of the existing literature, as is our finding of $\mathrm{AD}$ as a persistent learning-need for GP registrars. As yet, there is limited literature to compare our findings of registrar AD referral pathways, and the implications of specialist choice on clinical outcomes. 


\section{Strengths and Limitations}

This study has a number of strengths, in particular, its high response rate $(96.1 \%)$ and broad data set $(595,412$ data points) and geographic distribution throughout areas classified as urban, rural, and remote across multiple Australian states. As such, findings are generalizable across Australia and, potentially, internationally. A limitation of the analysis was the limited clinical context provided within the consultation data. We did not have contextual information on severity of $\mathrm{AD}$, of $\mathrm{AD}$ past history, of medicine regimens, of concurrent conditions and, thus, were unable to ascertain if individual referrals were appropriate for care escalation.

\section{Implications for Practice and Future Research}

Our findings suggest that registrars are engaging with diagnosis and management of $\mathrm{AD}$, but that $\mathrm{AD}$ (as with skin disease generally), remains a priority learning-need for registrars. Continued reevaluation of postgraduate dermatology curricula would best focus on management components and understanding of appropriate indications for referral. Clarification, such as through referral pathways, for specific specialist involvement would help to guide appropriate specialist referral according to patient presentation. Furthering awareness of and access to multidisciplinary clinics, wherein a variety of specialists are available, may also help to optimize GP registrars' contribution to $\mathrm{AD}$ management.

\section{Conclusions}

Our findings show that GP registrars are engaging with $\mathrm{AD}$, yet it is apparent this is still a learning-need for many registrars. Registrar education could include appropriate referral pathways and further clarification regarding the role of allergy in $\mathrm{AD}$.

\section{References}

1. Drucker AM, Wang AR, Li WQ, Sevetson E, Block JK, Qureshi AA. The burden of atopic dermatitis: summary of a report for the National Eczema Association. J Invest Dermatol. 2017;137(1):2630. DOI: 10.1016/j.jid.2016.07.012. PMID: 27616422.

2. Beattie PE, Lewis-Jones MS. A comparative study of impairment of quality of life in children with skin disease and children with other chronic childhood diseases. Br J Dermatol. 2006;155(1):145-151. DOI: 10.1111/j.1365-2133.2006.07185.x. PMID: 16792766.

3. Asher MI, Montefort S, Bjorksten B, et al. Worldwide time trends in the prevalence of symptoms of asthma, allergic rhinoconjunctivitis, and eczema in childhood: ISAAC Phases One and Three repeat multicountry cross-sectional surveys. Lancet. 2006;368(9537):733743. DOI: 10.1016/S0140-6736(06)69283-0.

4. Kay J, Gawkrodger DJ, Mortimer MJ, Jaron AG. The prevalence of childhood atopic eczema in a general population.
J Am Acad Dermatol. 1994;30(1):35-39. DOI: 10.1016/s01909622(94)70004-4

5. Mortz CG, Andersen KE, Dellgren C, Barington T, BindslevJensen C. Atopic dermatitis from adolescence to adulthood in the TOACS cohort: prevalence, persistence and comorbidities. Allergy. 2015;70(7):836-845. DOI: 10.1111/all.12619. PMID: 25832131.

6. Eichenfield LF, Boguniewicz M, Simpson EL, Russell JJ, Block JK, Feldman SR, et al. Translating Atopic Dermatitis Management Guidelines Into Practice for Primary Care Providers. Pediatrics. 2015;136(3):554-565. DOI: 10.1542/peds.2014-3678. PMID: 26240216.

7. Whiting G, Magin P, Morgan S, et al. General practice trainees' clinical experience of dermatology indicates a need for improved education: A cross-sectional analysis from the Registrar Clinical Encounters in Training Study. Australas J Dermatol. 2017;58(4):e199-e206. DOI: 10.1111/ajd.12493. PMID: 27301794.

8. Harris VR, Cooper AJ. Atopic dermatitis: the new frontier. Med J Aust. 2017;207(8):351-356. DOI: 10.5694/mja17.00463. PMID: 29020907.

9. Weidinger S, Novak N. Atopic dermatitis. Lancet. 2016;387(10023):1109-1122. DOI: 10.1016/S0140-6736(15) 00149-X.

10. Atopic Dermatitis. eTG Complete; [updated 2019 Jun]. Accessed January 30, 2020. https://tgldcdp.tg.org.au/viewTopic?topicfile=dermatitis\&guidelineName=Dermatology\#toc_d1e129.

11. Rubsam ML, Esch M, Baum E, Bosner S. Diagnosing skin disease in primary care: a qualitative study of GPs' approaches. Fam Pract. 2015;32(5):591-595. DOI: 10.1093/fampra/cmv056. PMID: 26160890.

12. Moreno G, Tran H, Chia AL, Lim A, Shumack S. Prospective study to assess general practitioners' dermatological diagnostic skills in a referral setting. Australas J Dermatol. 2007;48(2):7782. DOI: 10.1111/j.1440-0960.2007.00340.x. PMID: 17535192.

13. Le Roux E, Powell K, Banks JP, Ridd MJ. GPs' experiences of diagnosing and managing childhood eczema: a qualitative study in primary care. Br J Gen Pract. 2018;68(667):e73-e80. DOI: 10.3399/bjgp18X694529. PMID: 29335327.

14. Smith SD, Harris V, Lee A, Blaszczynski A, Fischer G. General practitioners knowledge about use of topical corticosteroids in paediatric atopic dermatitis in Australia. Aust Fam Physician. 2017;46(5):335-340.

15. Whitaker-Worth DL, Susser WS, Grant-Kels JM. Clinical dermatologic education and the diagnostic acumen of medical students and primary care residents. Int J Dermatol. 1998;37(11):855-859. DOI: 10.1046/j.1365-4362.1998.00537.x. PMID: 9865874.

16. Singh DG, Boudville N, Corderoy R, Ralston S, Tait CP. Impact on the dermatology educational experience of medical students with the introduction of online teaching support modules to help address the reduction in clinical teaching. Australas J Dermatol. 2011;52(4):264-269. DOI: 10.1111/j.1440-0960.2011.00804.x. PMID: 22070700.

17. Gupta A, Chong AH, Scarff CE, Huilgol SC. Dermatology teaching in Australian Medical Schools. Australas J Dermatol. 2017;58(3):e73-e78. DOI: 10.1111/ajd.12486. PMID: 27145418.

18. Sladden MJ, Graham-Brown RA. How many GP referrals to dermatology outpatients are really necessary? J R Soc Med. 1989;82(6):347-348. DOI: 10.1177/014107688908200611. PMID: 2810314 
19. van Rijsingen MC, Hanssen SC, Groenewoud JM, van der Wilt GJ, Gerritsen MJ. Referrals by general practitioners for suspicious skin lesions: the urgency of training. Acta Derm Venereol. 2014;94(2):138-41. DOI: 10.2340/00015555-1752. PMID: 24352366.

20. Britt H. A new coding tool for computerised clinical systems in primary care--ICPC plus. Aust Fam Physician. 1997;26 Suppl 2:S79-82.

21. Britt H, Miller GC, Henderson J, et al. General practice activity in Australia 2015-16. Sydney University Press; 2016.

22. Magin P, Morgan S, Wearne S, et al. GP trainees' in-consultation information-seeking: associations with human, paper and electronic sources. Fam Pract. 2015;32(5):525-532. DOI: 10.1093/ fampra/cmv047. PMID: 26089297.

23. Magin P, Tapley A, Davey A, et al. General practitioner trainees' in-consultation generation of clinical questions for later answering: prevalence and associations. Fam Pract. 2017;34(5):599-605. DOI: 10.1093/fampra/cmx021. PMID: 28369454.

24. Tng ETV, Tapley A, Davey A, et al. General practice registrars' clinical exposure to dermatological procedures during general practice training: a cross-sectional analysis. Educ Prim Care. 2018;29(6):357-366. DOI: 10.1080/14739879.2018.1520612. PMID: 30311852.

25. Eichenfield LF, Ahluwalia J, Waldman A, Borok J, Udkoff J, Boguniewicz M. Current guidelines for the evaluation and man- agement of atopic dermatitis: A comparison of the Joint Task Force Practice Parameter and American Academy of Dermatology guidelines. J Allergy Clin Immunol. 2017;139(4S):S49-S57. DOI: 10.1016/j.jaci.2017.01.009. PMID: 28390477

26. Saavedra JM, Boguniewicz M, Chamlin S, Lake A, Nedorost S, Czerkies LA, et al. Patterns of clinical management of atopic dermatitis in infants and toddlers: a survey of three physician specialties in the United States. J Pediatr. 2013;163(6):1747-1753. DOI: 10.1016/j.jpeds.2013.06.073. PMID: 23953725.

27. Mohan GC, Lio PA. Comparison of dermatology and allergy guidelines for atopic dermatitis management. JAMA Dermatol. 2015;151(9):1009-13.10.1001/jamadermatol.2015.0250. PMID: 25853940.

28. Werfel T, Ballmer-Weber B, Eigenmann PA, et al. Eczematous reactions to food in atopic eczema: position paper of the EAACI and GA2LEN. Allergy. 2007;62(7):723-728. DOI: 10.1111/j.13989995.2007.01429.x. PMID: 17573718.

29. Wuthrich B. Food-induced cutaneous adverse reactions. Allergy. 1998;53(46 Suppl):131-135. DOI: 10.1111/j.1398-9995.1998. tb04983.x. PMID: 9826020.

30. Thompson MM, Tofte SJ, Simpson EL, Hanifin JM. Patterns of care and referral in children with atopic dermatitis and concern for food allergy. Dermatol Ther. 2006;19(2):91-96. DOI: 10.1111/j.1529-8019.2006.00062.x. PMID: 16669991. 